\title{
ANALISIS KAPASITAS RUNWAY BANDARA I GUSTI NGURAH RAI MENGGUNAKAN TEORI ANTREAN
}

\author{
Khosyi Rukito $^{1 \S}$, I Wayan Sumarjaya ${ }^{2}$, I Gusti Ayu Made Srinadi ${ }^{3}$ \\ ${ }^{1}$ Program Studi Matematika, Fakultas MIPA - Universitas Udayana [Email: rukitokhosyi@gmail.com] \\ ${ }^{2}$ Program Studi Matematika, Fakultas MIPA - Universitas Udayana [Email: sumarjaya@unud.ac.id] \\ ${ }^{3}$ Program Studi Matematika, Fakultas MIPA - Universitas Udayana [Email: srinadi@ unud.ac.id] \\ ${ }^{\S}$ Corresponding Author
}

\begin{abstract}
Bali, as one of the world's tourism destination, located separately from other islands in Indonesia. Many tourists travel to Bali by airplane, and I Gusti Ngurah Rai Airport is the only international airport that serves as the main gate to Bali. There are situations in which the airport's runway often has to deal with an extensive queue for both landing and departure, which results in flight delays. Flight delays have caused some problems such as ruin airlines reputation and decline demand by passangers. The aim of the research is to analyze the efficiency of I Gusti Ngurah Rai International Airport's runway so the airport service can be optimized using queueing theory. In this research, there were four categories used: the high season in July 2018, the special event Annual Meeting International Monetary Fund-World Bank in October 2018, the low season in February 2019, and the overall data. In this research, it was found that the model used in this airport's runway is $(M / G / I):(F I F O / \infty / \infty)$. This model is not in a steady-state condition, with the level of bustle approximately around $177 \%$ until 191\%. Therefore, an additional runway is recommended and also the runway service needs to be accelerated for optimal condition.
\end{abstract}

Keywords: Bali, I Gusti Ngurah Rai International Airport, Service, Runway, Queueing Theory.

\section{PENDAHULUAN}

Budaya dan keindahan alam yang ada membuat Bali menjadi salah satu destinasi wisata dunia. Hal tersebut menyebabkan banyak wisatawan dari dalam negeri maupun mancanegara datang ke Bali. Selain itu, Bali juga dijadikan tempat pertemuan berskala nasional maupun internasional, salah satunya Annual Meeting International Monetary Fund World Bank 2018. Menurut BPS (2019) jumlah wisatawan mancanegara yang masuk ke Provinsi Bali meningkat setiap tahunnya dan mencapai enam juta jiwa pada tahun 2018.

Bali terletak di bagian tengah Indonesia serta memiliki bentuk pulau yang terpisah dari pulau lain. Banyak wisatawan memilih untuk menggunakan moda transportasi pesawat udara guna mencapai akses menuju Bali. Sehingga, bandar udara mempunyai peranan yang penting.

Saat ini Provinsi Bali hanya memiliki satu bandar udara yaitu Bandar Udara Internasional I Gusti Ngurah Rai yang terletak di bagian selatan Provinsi Bali, tepatnya di Kabupaten Badung.
Salah satu aspek yang dibutuhkan dalam manajemen keselamatan bandar udara adalah landasan pacu (runway) sebagai tempat untuk melakukan lepas landas atau mendaratnya sebuah pesawat. Mengingat ketika melakukan lepas landas atau pendaratan pesawat membutuhkan ruang untuk mengendalikan kecepatan pesawat udara yang cukup tinggi, maka dalam waktu yang bersamaan pemakaian satu buah runway hanya bisa digunakan oleh satu buah pesawat untuk lepas landas ataupun mendarat.

Bandar Udara Internasional I Gusti Ngurah Rai hanya memiliki satu buah runway. Pada waktu tertentu bandara ini mengalami penumpukan antrean (holding) untuk menggunakan runway setiap harinya. Penumpukan antrean yang memakan waktu ini menjadi salah satu faktor penyebab terjadinya keterlambatan penerbangan (delay) terlebih lagi jika terdapat kegiatan-kegiatan berskala nasional ataupun internasional yang sedang dilaksanakan 
di Bali.

Keterlambatan penerbangan merupakan hal yang ditakuti oleh semua maskapai karena kualitas pelayanan dan kepercayaan konsumen bergantung salah satunya kepada ketepatan waktu penerbangan yang dijanjikan. Selain pelayanan teknis maskapai penerbangan, kesibukan runway juga menentukan ketepatan waktu. Oleh karena itu, perlu diadakan penelitian untuk menganalisis efektivitas kapasitas runway bandar udara ini agar nanti jumlah runway yang ada dapat menunjang segala kesibukan perputaran pesawat yang akan melakukan lepas landas maupun pendaratan.

Suatu cara yang bisa digunakan untuk mengukur kapasitas runway bandar udara yaitu menggunakan teori antrean guna menganalisis tingkat kesibukan serta kebutuhan runway dari bandar udara ini. Menurut Serlina (2018) teori antrean adalah sebuah teori yang berkaitan dengan studi matematis dari sebuah keadaan dimana terjadi hubungan antara sistem pelayanan (baik barang ataupun jasa) dengan pelanggan secara efektif, singkatnya adalah upaya penguraian waktu tunggu yang terjadi dalam barisan sebuah antrean.

Menurut Kakiay (2004) tujuan teori antrean adalah untuk meneliti ukuran kinerja sebuah fasilitas pelayanan dari sistem antrean yang ada dalam rangkaian keadaan acak. Menurut Bhat (2008) teori antrean membantu fasilitas pelayanan untuk dapat menyediakan pelayanan dengan teratur dan dapat bermanfaat, dengan begitu dapat memberikan informasi mengenai hal-hal yang dibutuhkan dalam membuat keputusan seperti gambaran karakteristik dan baris penungguan, salah satunya rata-rata waktu penungguan.

Tujuan teori antrean yaitu penggunaan sebuah sistem untuk mengatasi permintaan pelayanan (kedatangan pelanggan) yang tidak dapat diprediksi dan mengendalikan keseimbangan antara biaya (waktu sibuk), pelayanan, dan biaya (waktu menganggur) selama proses antrean terjadi dengan tiga komponen dasar antrean yaitu kedatangan, pelayanan, dan antrean.

Menurut Kakiay (2004), dalam teori antrean terdapat empat stuktur dasar proses antrean yaitu satu saluran satu tahap (single channel single phase), satu saluran banyak tahap (single channel multiple phase), banyak saluran satu tahap (multiple channel single phase), dan banyak saluran banyak tahap (multiple channel multiple phase).
Terdapat pula empat disiplin antre dalam teori antrean, yaitu first in first out (FIFO) di mana sistem pelayanan akan melayani pelanggan yang datang terlebih dahulu, yang kedua adalah last in first out (LIFO) di mana terlebih dahulu sistem akan melayani pelanggan yang datang terakhir, selanjutnya adalah service in random order (SIRO) merupakan sebuah pelayanan dalam antrean di mana akan dilayani secara acak tanpa memperhatikan kedatangan ataupun prioritas dalam sebuah sistem, dan terakhir adalah priority service (PS) merupakan sebuah pelayanan di mana pelanggan dengan prioritas atau urgensi lebih tinggi akan dilayani terlebih dahulu dibandingkan yang lain dengan tidak mempertimbangkan urutan kedatangan.

Menurut Taha (1997) dalam teori antrean terdapat sebuah notasi untuk menyatakan model antrean yang disebut notasi Kendall-Lee yang dirancang oleh Kendall dan Lee dengan notasi $(a / b / c):(d / e / f)$ dengan a merupakan distribusi kedatangan, $b$ merupakan distribusi pelayanan, $c$ adalah jumlah pelayanan parallel dengan $c=1,2, \ldots, \infty, d$ adalah disiplin pelayanan, $e$ merupakan jumlah maksimal yang diizinkan ada di sistem baik antrean atau pelayanan, serta $f$ merupakan jumlah pelanggan sebagai sumber yang ingin memasuki sistem.

Notasi dalam simbol $a$ dan $b$ dapat diganti dengan $M$ apabila kedatangan merupakan distribusi Poisson atau waktu pelayanan berdistribusi eksponensial, $D$ jika waktu pelayanan konstan atau deterministik, $G$ jika waktu pelayanan berdistribusi umum, di mana distribusi umum merupakan penolakan terhadap distribusi Poisson atau distribusi eksponensial pada saat uji satu sampel Kolmogorov-Smirnov. Distribusi umum menunjukkan bahwa kedatangan atau pelayanan bergantung pada sebelum ataupun sesudahnya.

Notasi dalam simbol $c$ dapat diganti dengan I jika pelayanan bersifat tunggal, dan sebaliknya jika pelayanan ganda dapat diganti dengan simbol $C$. Notasi dalam simbol $d$ dapat diganti dengan GI jika waktu kedatangan berdistribusi umum, dan $G D$ jika general discipline (disiplin umum) dalam antrean (FIFO, LIFO, SIRO, atau PS).

Setelah didapatkan notasi Kendall-Lee, terdapat beberapa model antrean, menurut Aminuddin (2015) diantaranya adalah $(M / M /$ $I):(F I F O / \infty / \infty), \quad(M / D / I):(F I F O / \infty / \infty)$, $(M / G / I):(G D / \infty / \infty),(M / G / C):(G D / \infty / \infty)$. 
Selanjutnya untuk mengukur kesetimbangan sistem antrean di mana sebuah antrean berada di dalam keadaan setimbang atau tidak berubah lagi sesuai dengan berjalannya waktu yang disebut dengan keadaan steady state $(u)$, yaitu:

$$
u=\frac{\lambda}{c \mu} \leq 1
$$

dengan $\lambda$ merupakan rata-rata waktu kedatangan, c adalah jumlah sistem pelayanan yang ada, dan $\mu$ adalah rata-rata waktu pelayanan. Jika suatu kondisi tidak memenuhi keadaan steady state maka jumlah sumber pelayanan harus ditambah atau mempercepat waktu kedatangan dan waktu pelayanan barulah dapat dianalisis ukuran kinerja situasi antrean.

Dari uraian di atas, penulis ingin menganalisis kapasitas runway Bandar Udara Internasional I Gusti Ngurah Rai, Bali menggunakan teori antrean guna mengetahui model antrean, tingkat kesibukan serta kebutuhan jumlah runway yang efektif untuk diterapkan di bandara ini.

\section{METODE PENELITIAN}

\subsection{Teknik Pengumpulan Data}

Penelitian dilakukan di Bandar Udara Internasional I Gusti Ngurah Rai, Bali dengan data primer dan sekunder. Pengambilan data dilakukan melalui tiga cara yaitu (1) observasi langsung untuk mengetahui aircraft movement yang ada, (2) wawancara dengan petugas ATC Bandara I Gusti Ngurah Rai, dan (3) studi literatur.

\subsection{Teknik Analisis Data}

Dalam penelitian ini, analisis data dilakukan dalam enam tahap, yaitu (1) Mencari nilai $\lambda$ dan $\mu$ dengan input data waktu kedatangan, waktu dimulainya pelayanan dan waktu pelayanan berakhir; (2) Masing-masing data dilakukan uji kecocokan distribusi: distribusi Poisson untuk waktu kedatangan dan distribusi eksponensial untuk waktu pelayanan; (3) Penentuan model antrean; (4) Melakukan pengecekan steady state dari model yang diperoleh; (5) Pengambilan keputusan dari model yang diperoleh adalah sebagai berikut: jika steady state terpenuhi maka dapat dilakukan perhitungan dan analisis data namun jika steady state tidak terpenuhi maka waktu pelayanan dipercepat atau menambah jumlah sistem pelayanan, barulah dapat dilakukan perhitungan dan analisis data jika steady state terpenuhi; dan (6) Melakukan perhitungan dan analisis data berupa jumlah rata-rata waktu tunggu pelanggan dalam antrean $\left(W_{q}\right)$, jumlah rata-rata waktu menunggu pelanggan dalam sistem $\left(W_{S}\right)$, jumlah pelanggan rata-rata dalam antrean $\left(L_{q}\right)$, dan rata-rata jumlah pelanggan dalam sistem $\left(L_{S}\right)$.

Teknik analisis data dalam penelitian ini dapat dilihat pada Gambar 1. 


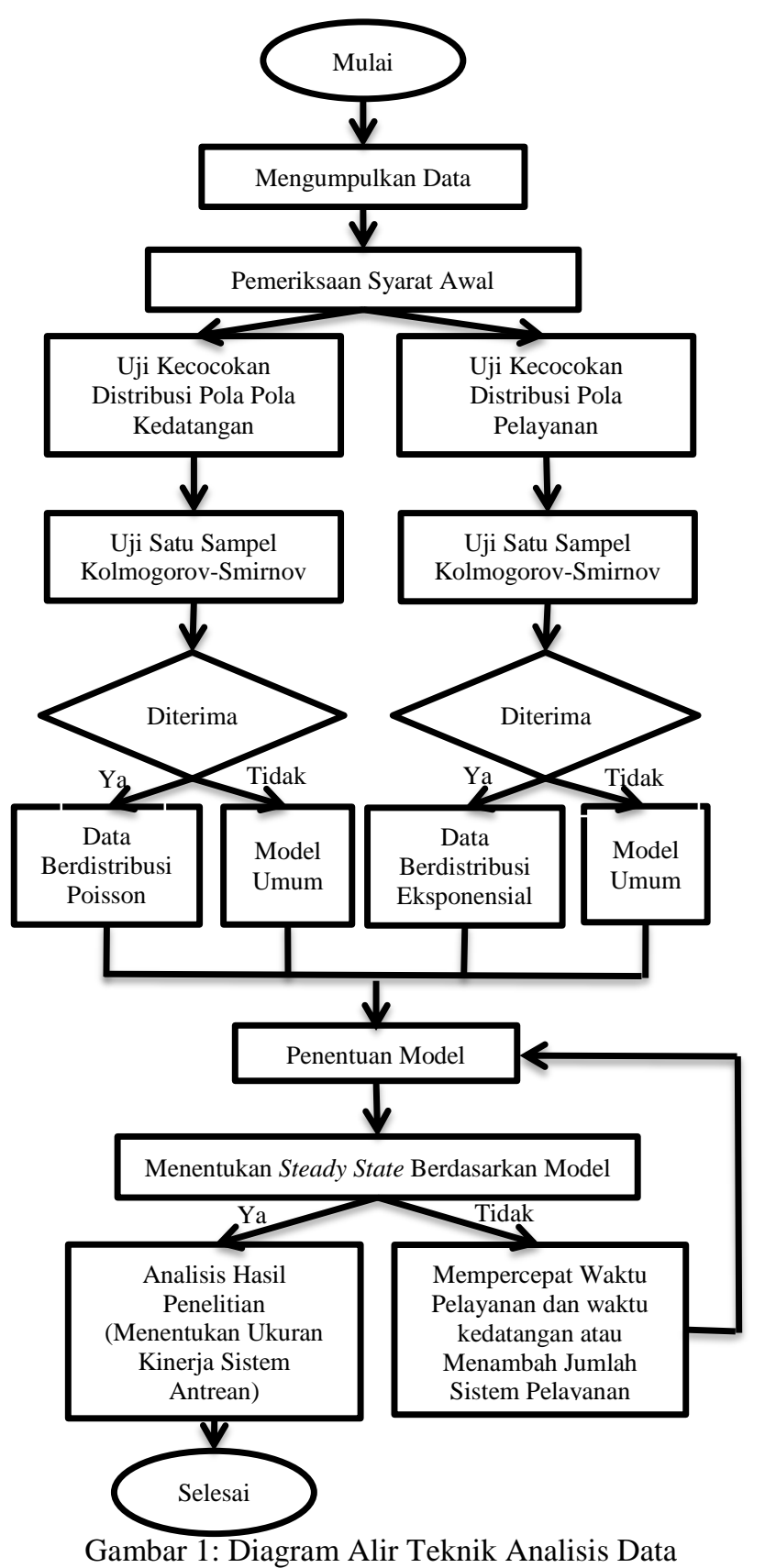

\section{HASIL DAN PEMBAHASAN}

Berdasarkan hasil analisis data yang dilakukan berdasarkan data saat high season pada Juli 2018, kejadian khusus saat pelaksanaan Annual Meeting International Monitary FundWorld Bank 2018 pada Oktober 2018, dan low season pada Februari 2019, dan data secara keseluruhan yang didapat dari ATC Wilayah Denpasar, diperoleh bahwa model antrean yang ada di Bandar Udara Internasional I Gusti Ngurah Rai, Bali adalah $(M / G / I):(F I F O / \infty /$ $\infty)$. Setelah didapatkan model antrean yang ada di runway bandara ini, langkah selanjutnya adalah menentukan steady state. Setelah dilakukan perhitungan diketahui runway bandara ini berada dalam keadaan tidak steady state atau dalam keadaan tidak setimbang karena $u>1$. Tingkat kesibukan berkisar antara $177 \%$ sampai dengan 191\%. Dengan demikian diperlukan penambahan jumlah sumber pelayanan dalam hal ini adalah runway.

Dengan mengasumsikan penambahan jumlah runway menjadi dua buah runway didapatkan bahwa model antrean yang ada menjadi $(M / G / C):(F I F O / \infty / \infty)$ dengan $c=2$. Berdasarkan analisis yang dilakukan dengan menambah jumlah runway, keempat kategori sudah dalam keadaan steady state atau dalam keadaan setimbang dengan tingkat kesibukan berkisar antara $89 \%$ sampai dengan $95 \%$. Hasil pengukuran steady state dan kesibukan runway yang ditunjukkan di Tabel 1. 
Tabel 1. Hasil Pengukuran Steady State dan Kesibukan Runway Bandar Udara.

\begin{tabular}{ccccc}
\hline Kategori & $\begin{array}{c}\text { High Season } \\
(\text { Juli 2018) }\end{array}$ & $\begin{array}{c}\text { Annual Meeting } \\
\text { IMF-WB 2018 } \\
\text { (Oktober 2018) }\end{array}$ & $\begin{array}{c}\text { Low Season } \\
\text { (Februari 2019) }\end{array}$ & $\begin{array}{c}\text { Data } \\
\text { Keseluruhan }\end{array}$ \\
\hline$\lambda$ & 0,26 & 0,23 & 0,26 & 0,25 \\
\hline$\mu$ & 0,13 & 0,13 & 0,15 & 0,13 \\
\hline $\begin{array}{c}\text { Jumlah runway } \\
\text { (Saat ini) }\end{array}$ & 1 & 1 & 1 & 1 \\
\hline $\begin{array}{c}\text { Pengukuran } \\
\text { steady state }(u)\end{array}$ & 1,91 & 1,81 & 1,77 & 1,85 \\
\hline $\begin{array}{c}\text { Steady State } \\
\text { Jumlah runway } \\
\text { (Assumsi awal) }\end{array}$ & Tidak & Tidak & Tidak & Tidak \\
\hline $\begin{array}{c}\text { Pengukuran } \\
\text { steady state }(u)\end{array}$ & 0,95 & 2 & 2 & 2 \\
\hline Steady state & Ya & 0,91 & 0,89 & 0,93 \\
\hline Sunter & 2 & Ya & Ya & Ya \\
\hline
\end{tabular}

Sumber: data primer (2019), dianalisis.

Setelah sistem sudah dalam keadaan steady state langkah berikutnya adalah melakukan analisis perhitungan dengan model $(M / G /$ $C)$ : $($ FIFO $/ \infty / \infty)$. Perhitungan ini meliputi:

1. Perhitungan jumlah rata-rata waktu menunggu pelanggan dalam antrean $\left(W_{q}\right)$, dimana

$W_{q}=\frac{\lambda^{c} E\left[t^{2}\right](E[t])^{c-1}}{2(c-1) !(c-\lambda E[t])^{2}\left[\sum_{n=0}^{c-1} \frac{(\lambda E[t])^{n}}{n !}+\frac{(\lambda E[t])^{c}}{(c-1) !(c-\lambda E[t])}\right]}$.

2. Rata-rata jumlah pelanggan dalam antrean $\left(L_{q}\right)$, dimana

$$
L_{q}=\lambda \cdot W_{q} .
$$

3. Jumlah pelanggan rata-rata dalam sistem $\left(L_{S}\right)$, dimana

$$
L_{s}=L_{q}+\lambda E(t)
$$

4. Jumlah rata-rata waktu tunggu pelanggan dalam sistem $\left(W_{S}\right)$, dimana

$$
W_{s}=\frac{L_{s}}{\lambda}
$$

Perhitungan selengkapnya dapat dilihat pada Tabel 2.

Perhitungan pada saat high season menghasilkan jumlah rata-rata waktu menunggu pelanggan dalam antrean $\left(W_{q}\right)$ 19,15 menit, rata-rata waktu tunggu pelanggan dalam sistem $\left(W_{s}\right)$ 26,55 menit, rata-rata jumlah pelanggan dalam antrean $\left(L_{q}\right)$ adalah 5 pesawat, dan jumlah rata-rata pelanggan dalam sistem $\left(L_{S}\right)$ adalah 7 pesawat.
Tabel 2. Analisis Perhitungan

\begin{tabular}{ccccc}
\hline \multirow{2}{*}{ Kategori } & \multicolumn{2}{c}{$W_{q}$} & $W_{s}$ & \multicolumn{2}{c}{$L_{q}$} & $L_{s}$ \\
\cline { 2 - 5 } & \multicolumn{2}{c}{ (Dalam menit) } & \multicolumn{2}{c}{ (Pesawat) } \\
\hline $\begin{array}{c}\text { High Season } \\
\text { (Juli 2018) }\end{array}$ & 19,15 & 26,55 & 5 & 7 \\
\hline $\begin{array}{c}\text { Annual } \\
\text { Meeting IMF- } \\
\text { WB 2018 } \\
\text { (Oktober } \\
\text { 2018) }\end{array}$ & 10,19 & 18,17 & 3 & 5 \\
\hline $\begin{array}{c}\text { Low Season } \\
\text { (Februari } \\
\text { 2019) }\end{array}$ & 6,97 & 13,68 & 2 & 4 \\
\hline $\begin{array}{c}\text { Data } \\
\text { Keseluruhan }\end{array}$ & 12,34 & 19,84 & 4 & 5 \\
\hline Sumber: data primer & & & & \\
\hline
\end{tabular}

Sumber: data primer (2019), dianalisis.

Selanjutnya, pada saat kejadian khusus Annual Meeting IMF-WB 2018 rata-rata waktu tunggu pelanggan dalam antrean $\left(W_{q}\right) \quad 10,19$ menit, waktu tunggu rata-rata pelanggan dalam sistem $\left(W_{s}\right)$ 18,17 menit, jumlah rata-rata pelanggan dalam antrean $\left(L_{q}\right)$ adalah 3 pesawat, serta rata-rata pelanggan dalam sistem $\left(L_{s}\right)$ adalah 5 pesawat.

Saat low season waktu tunggu rata-rata pelanggan dalam antrean $\left(W_{q}\right)$ 6,97 menit, jumlah rata-rata waktu tunggu pelanggan dalam sistem $\left(W_{s}\right)$ 13,68 menit, rata-rata jumlah pelanggan dalam antrean $\left(L_{q}\right)$ adalah 2 pesawat, jumlah rata-rata pelanggan dalam sistem $\left(L_{S}\right)$ adalah 4 pesawat. 
Terakhir, untuk data keseluruhan rata-rata waktu tunggu pelanggan dalam antrean $\left(W_{q}\right)$ 12,34 menit, jumlah waktu tunggu rata-rata pelanggan dalam sistem $\left(W_{s}\right)$ 19,84 menit, jumlah rata-rata pelanggan dalam antrean $\left(L_{q}\right)$ adalah 4 pesawat, dan jumlah rata-rata pelanggan dalam sistem $\left(L_{S}\right)$ adalah 5 pesawat.

\section{KESIMPULAN DAN SARAN}

\subsection{Kesimpulan}

Dari hasil dan analisis yang telah dilakukan pada empat kondisi, yaitu high season, kejadian khusus saat pelaksanaan Annual Meeting International Monetary Fund - World Bank 2018, low season dan data secara keseluruhan mengenai efektivitas runway bandara ini diketahui bahwa model antrean yang ada saat ini di runway Bandar Udara Internasional I Gusti Ngurah Rai, Bali adalah $(M / G /$ $I):(F I F O / \infty / \infty)$ namun tidak memenuhi kondisi steady state dengan tingkat kesibukan berkisar antara $177 \%$ sampai dengan $191 \%$. Sehingga, diperlukan untuk diadakan penambahan jumlah sumber pelayanan dalam hal ini adalah runway bandar udara. Sehingga, model antrean yang ada nantinya adalah $(M / G / C):(F I F O / \infty / \infty)$, dalam hal ini sumber pelayanan menjadi dua buah runway. Sehingga, dengan diadakannnya penambahan jumlah runway tingkat kesibukan di runway Bandar Udara Internasional I Gusti Ngurah Rai, Bali adalah $89 \%$ sampai dengan $95 \%$.

\subsection{Saran}

(1) Berdasarkan analisis tingkat kesibukan pada penelitian ini berkisar antara $89 \%$ sampai dengan 95\% pada saat setelah jumlah runway telah ditambah maka selain menambah jumlah sumber pelayanan dalam hal ini runway bandar udara disarankan pula untuk mempercepat lama waktu tunggu dan waktu lama pelayanan agar tidak mengorbankan waktu salah satu proses baik take off ataupun landing sehingga kesibukan runway Bandar Udara Internasional I Gusti Ngurah Rai, Bali dapat menurun; (2) Mengingat penelitian ini hanya berfokus pada tingkat kesibukan runway, maka untuk penelitian selanjutnya disarankan untuk mempertimbangkan faktor lain yang dapat mempengaruhi pelayanan di runway Bandar Udara Internasional I Gusti Ngurah Rai, Bali seperti faktor biaya, dan sumber daya manusia, sumber daya alam dan lain-lain.

\section{DAFTAR PUSTAKA}

Aminudin. (2005). Prinsip-prinsip Riset Operasi. Jakarta: Erlangga.

Bhat, U. N. (2008). An Introduction to Queueing Theory. Dallas: Birkhåuser.

Kakiay, T. J. (2004). Dasar Teori Antrian untuk Kehidupan Nyata. Yogyakarta: Andi Offset.

Serlina, L. (2018). Analisis Sistem Antrian Pelanggan Bank Rakyat Indonesia (BRI) Cabang Bandar lampung Menggunakan Model Antrian Multi Channel-Single Phase. Lampung: UIN Raden Inten Lampung.

Taha, H. A. (1997). Riset Operasi Jilid Dua Edisi Kelima. Jakarta: Binarupa Aksara. 